\title{
Estimating the amount of cold water wastage in UK households
}

1 Rizwan Nawaz PhD, MCIWEM, CEnv, CWEM, FRGS, FHEA Research Coordinator, water@leeds, University of Leeds, Leeds, UK
2 Booker G. K. Waya MSc

Engineer, Blantyre Water Board, Blantyre, Malawi

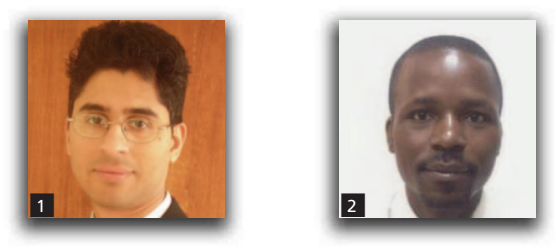

Current and future water demand pressures arising from inadequate supplies and forecasts of increased population in the UK have prompted the government and other stakeholders to set up strategies that will ensure sustainable water supplies. Demand-side management strategies are one of the key priorities being pursued and the water regulator, Ofwat, has set a target of 13\% reduction from 2010 levels of per capita household water consumption in England and Wales by 2030. This paper reports on estimated water wastage in UK households resulting from users waiting for water to reach a sufficiently warm temperature when using a hot water outlet (including kitchen sinks, showers and hand wash basins). It is estimated that, on average, $10 \%$ of the daily average per capita water consumption in UK households is wasted in this way. Possible means of reducing this waste are identified and a recommendation is made that boilers should carry a water efficiency rating in addition to the standard energy efficiency rating.

\section{Introduction}

The current average domestic per capita consumption (PCC) in England and Wales for unmetered customers is 1501 (Defra, 2008; Ofwat, 2010), significantly above that in some other European countries such as Finland and Belgium (Environment Agency, 2008). In parts of south east and eastern England, the PCC is over 1601 for unmetered connections. Ironically, these regions are among the most water stressed areas in the UK, receiving less rain than parts of the Mediterranean region (Environment Agency, 2008). The pressure on water resources is unlikely to ease given the future prospects of increased frequency of drier weather and population growth (Defra, 2011). The population in the UK is expected to rise from 62.3 million in 2010 to $73 \cdot 2$ million by 2035 (ONS, 2011), and a key challenge facing water planners is that the largest proportion of population growth is expected to occur in the already water stressed areas (Defra, 2008).

The Environment Agency in England and Wales has adopted a twin-track approach to water management (Environment Agency, 2009) in which both supply- and demand-side options are considered. Supply-side options may include leakage reduction, increased resource capacity and water transfers, while demand-side options encourage water efficiencies and water saving behaviours among customers. This may be achieved through metering, the implementation of water-efficient appliances, and increasing customer education and awareness (Defra, 2008). The growing number of water demand management success stories (e.g. see Jordan, 2012; Nakagawa et al., 2010; NWC, 2012) indicates the good progress towards lowering household consumption made over recent years. Clearly, such efforts need to continue given the UK government target of lowering average household daily PCC from 1501 to 1301 by 2030 (Defra, 2011).

Water demand management strategies may either be price or nonprice related. The UK system, which is mainly characterised by water charges based on the rateable value of a property (Defra, 2011), is more focused on non-price demand management measures. The water regulator in England and Wales, Ofwat, does not advocate universal metering because it believes that, in many areas, the extra capital and operating costs of metering might outweigh the benefits in water savings. Ofwat is, however, in favour of compulsory universal metering in areas of severe water stress. Non-price-related measures for water demand management include raising customer awareness on the wise use of water, and the use of fittings and appliances that are more efficient (Ofwat, 2010).

The nexus of water and energy is now well recognised and it is estimated that domestic hot water use accounts for $5 \%$ of the total UK annual greenhouse gas emissions (Waterwise, 2012). According to another Ofwat estimate (Ofwat, 2010), UK water 
companies alone could reduce their greenhouse gas emissions by $8 \%$ if 201 of water per day were saved per household. Investigations focusing specifically on the energy savings from (hot) water-efficient technologies have also been conducted (e.g. Beal et al., 2012; Fidar et al., 2010) and quantify the dual savings that could be achieved through increased efficiency.

The government is therefore clearly keen to encourage reductions in PCC, and its long-term ambition is to see PCC reduced from the current level of 1501 to 1301 by 2030 through implementation of new technologies and innovation (Defra, 2008). To help achieve this target, Ofwat is encouraging water companies to aim for a lowering of water consumption by 11 per property per day over each of the 5 years from 2010 to 2015 (Ofwat, 2010).

The aim of this work was to estimate water wastage in UK households through hot water outlets, investigate the underlying reasons for this wastage and suggest possible solutions to the problem. The findings from this study should be useful to policy makers as they will help raise awareness of water efficiency and domestic water heating systems. The raised awareness and understanding should help towards reaching the reduced PCC targets set by the UK government.

\section{Hot water provision in UK households}

\subsection{Energy efficiency}

The two main types of hot water heating systems installed in UK households are conventional boilers and combination ('combi') boilers (Figure 1).

A conventional boiler works on the basis of 'heating only' and therefore requires a separate hot water cylinder (usually located in an airing cupboard) that stores a large amount of the household hot water. There are also two feeder tanks, usually located in the loft area. One of the tanks is for domestic hot water, which feeds through to the hot water storage cylinder. The second tank is required for central heating. Mains cold water is fed through the expansion/header tank to the central heating system, which is heated via the boiler.

In contrast, a combi boiler is generally considered to be the UK's most popular type of boiler. A combi boiler is a compact and energy-efficient unit and, unlike a conventional system, does not store domestic hot water. Water is heated directly from the cold mains and therefore results in significant reductions in water heating costs. Combi boilers are now in widespread use and it is known, for example, that they have represented $70 \%$ of all gas boiler installations in the UK for a number of years (HHWT, 2010).

Government efforts aimed at increasing household energy efficiency have, over the years, required more energy-efficient domestic hot water systems. From 2005 onwards, it has been mandatory for all new water heating boilers to be of the conden-

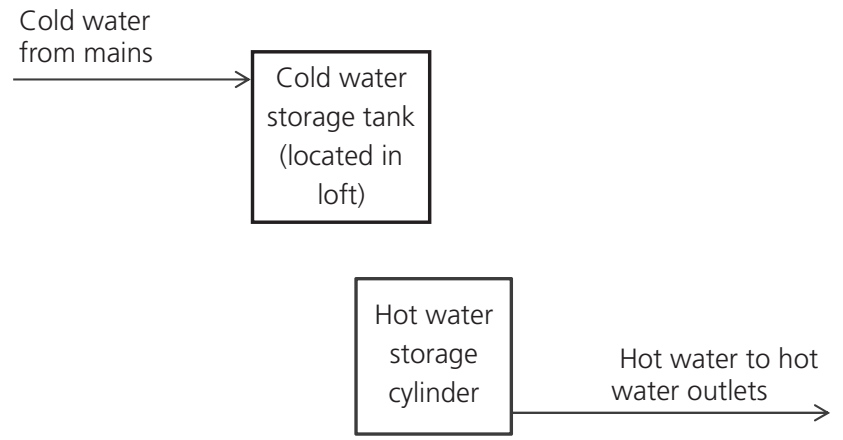

(a) Conventional boiler

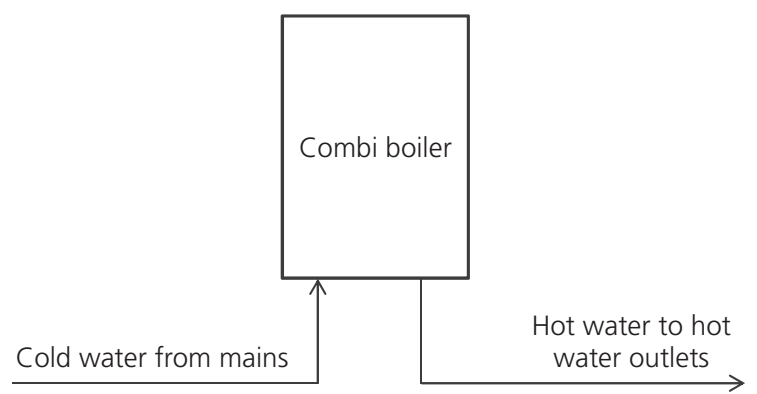

(b) Combi boiler

Figure 1. Schematic illustration of two types of boilers in common use in UK households

sing type, which are more energy efficient (Palmer and Cooper, 2011). Since October 2010 there has been a requirement for all new boiler installations to have the highest energy efficiency rating issued by the Energy Saving Trust (CEBR, 2011).

\subsection{Water efficiency}

While the drive for energy efficiency within domestic hot water supplies has resulted in significant energy savings, there has been less emphasis on water efficiency. There is, for example, some evidence to suggest that combi boilers lead to more water being wasted than conventional boilers. A study by the Energy Saving Trust (EST, 2008a) found that households with combi boilers used more water at the kitchen sink than those with conventional boilers. The reason for this is that householders require water at a higher temperature in the kitchen sink compared with other hot water outlets, which combi boilers take a little longer to deliver. As a result of this waiting time, more water is allowed to drain away as waste. This is an inevitable drawback of combi boilers from a water efficiency perspective, and occurs owing to the delay caused by the system control device first needing to sense the flow rate and temperature of the incoming water, and then allowing cold water to pass through (Grubb, 2006; Wickes, 2011). As noted by Grubb (2006) and EST (2008b), the delivery time for hot water to taps depends on the temperature of the water from the mains and on the length of piping between boilers and hot water outlets. Following on from this, it would not be unsurprising if, during winter months in particular, significant volumes of cold water were being allowed to drain away owing to the wait for a combi boiler 


\section{Offprint provided courtesy of www.icevirtuallibrary.com Author copy for personal use, not for distribution}

to provide hot water at the desired temperature and on demand. Waste is also likely in households with conventional boilers owing to standing water (in the pipework between the storage tank and the tap) becoming cool and therefore being discharged.

\section{Methodology}

\subsection{Data collection}

The basis for this investigation was a questionnaire survey distributed to individuals residing in the UK (excluding Northern Ireland). The survey, comprising 17 questions, was set up on www.surveymonkey.com, and, apart from containing background information to inform respondents about the nature of the study, it contained a data protection statement explaining that participation was purely voluntary. Only adults participated in the survey, and they were targeted through a variety of means, including mailing lists (academic staff, students, alumni, industry, personal), social media, websites, newsletters, and by personally approaching friends and family. Leeds University academic staff and student mailing lists were available to the authors while student lists for other universities in England, Wales and Scotland were made available by the Commonwealth Scholarship and Canon Collins Trust schemes (comprising 280 students).

Data generally provided by students residing in private accommodation rather than halls of residence proved suitable for the purposes of this research. The University of Leeds' water research centre website, twitter and LinkedIn sites were used to advertise the survey. Small advertisements were placed in several local newsletters (industry, environmental and faith groups). Hard copy questionnaires were also distributed through personal contacts to those individuals lacking access to the internet (e.g. the elderly). In total, 300 responses were collected (281 online and 19 hard copy). Of these, 108 surveys provided enough data suitable for analysis (the remaining respondents not having answered the most crucial questions). Respondents completed the survey during a 1-month period from mid-June to mid-July 2012. In accordance with the University of Leeds' ethics policy (UoL, 2008), potential participants were clearly informed about optional participation in the survey and complete anonymity. As noted earlier, only consenting adults participated in the survey.

Respondents were requested to provide details on frequency of use of various hot water outlets in the home. They were then asked if they, at times when using hot water outlets, left the water to drain while waiting for warm water to reach the desired temperature. Those who responded that they did were then asked to provide the name of the hot water outlet where this occurred, the season(s) in which this happened and the estimated distance from the boiler to the specified hot water outlet. For simplicity, householders were asked to report on two-dimensional Euclidean distances as opposed to pipe-run distances given the likely lack of knowledge of the domestic plumbing system. To enable estimation of volumes of unused water being left to drain, respondents were asked to determine the time it took waiting for warm water. Volumes could then be determined by multiplying with published tap/shower flow rates (see Section 3.2).

Respondents were also requested to complete an optional question requiring answers based on actual volume measurements. To enable reasonable uptake, various means of approximating the capacity were suggested, such as measuring jugs and empty milk/ cooking oil bottles. Clearly, estimates based on crude techniques such as these will, at best, be able to provide only a preliminary insight into the extent of the problem. It is also acknowledged that, in responding to the question, there may be the tendency for people to present a favourable image of themselves, thus leading to social desirability response (SDR) bias (van de Mortel, 2008). This is most likely to occur in responses to socially sensitive questions (King and Bruner, 2000). SDR bias could be one of the causes of water use misconceptions in self-reporting studies. For example, recent research from the bathroom manufacturer Ideal Standard (Rheinberg, 2012) showed that UK householders use five times the amount of water they think they do, despite $81 \%$ of those surveyed stating that they are conscious about their water usage.

Respondents were asked to indicate if they had a second shower unit and second hand wash basin in their homes. In this study, the first shower unit (designated 'shower 1') and the first hand wash basin (designated 'hand wash basin 1') were considered to mean those that were frequently used and probably more common in most households. 'Shower 2' and 'hand wash basin 2' referred to those that were either not common or not frequently used in most households. Gathering data on additional shower units and hand wash basins ensured that waste from these outlets would be analysed separately given their sometimes unique properties (e.g. considerable distances from the boiler and instantaneous electric showers). Respondents were also asked to provide the type of water heating (boiler) system they had, its age and whether it was classified as efficient or not.

To enable the survey to be completed in as short a time as possible, it was decided that most of the questions in the survey would be close-ended with a set of available answers to choose from (e.g. 'yes' or 'no', 'conventional' or 'combination', and scaled questions with answers such as ' $0-5$ seconds', ' $6-10$ seconds', etc.). To enable a high level of participation, the survey did not cover all aspects that may influence water wastage. For example, for households using hot water at regular intervals throughout the day (such as in the kitchen), waste would be reduced because water would have less chance of becoming cold as it would not be left to stand in pipes for significant periods. To help address this issue, it was decided to undertake a detailed investigation at the kitchen sink within one particular household with a combi boiler installation. Measurements were taken at first use in the morning ( $8.00 \mathrm{a} . \mathrm{m}$.), followed by further measurements at $5,10,15$ and 30 min intervals (8.05, 8.15, 8.30 and 9.00 a.m.). This was also repeated at lunchtime (12.00-1.00 p.m.). Volumes were estimated by collecting (using the kitchen sink plug) the water (usually allowed to drain away) and using a measuring jug. 
The measurement was repeated over three different days with different outside temperatures, and the results averaged.

\subsection{Data analysis}

The survey requested users to enter data as a range. To simplify analysis, it was decided to use the median values; for example, where the distance from boiler to kitchen sink was given to fall within the range of 1-2 $\mathrm{m}$, a distance of $1.5 \mathrm{~m}$ was used. While some survey respondents had provided measured volumes of water wasted, the majority had provided waiting times and these needed to be converted to volumes.

The conversion required estimated flow rates and an investigation into reported tap and shower flow rates revealed a limited number of published studies to draw on. In the UK, the Defra-funded Market Transformation Programme (MTP, 2008) reported a flow rate of $9.31 / \mathrm{min}$ for showers. Data from Australia indicated a range of 7-9 1/min for showers and 5-16 1/min for taps (Beal and Stewart, 2011). Anglian Water (2012) reported tap flow rates of $10-201 / \mathrm{min}$. On the basis of this information, it was decided to assume a flow rate of $91 / \mathrm{min}$ for a standard shower and hand wash basin. For the kitchen sink, a higher value of $12 \mathrm{l} / \mathrm{min}$ was used owing to the generally higher water pressure resulting from closer proximity of the sink to the water mains in UK households.

\section{Results}

The findings are categorised into three parts

whether cold water is allowed to drain away during different seasons of the year and the amount of losses where this occurs

- estimates of average per capita losses per day
- effects on losses at hot water outlet due to several factors, including distance from boiler, boiler type and efficiency rating/age.

It should be noted that in the subsequent discussion, the term 'water wastage' refers to the volumes of unused water allowed to drain away when using a hot water outlet such as a kitchen/ bathroom tap or shower. The water is allowed to drain as it is below the desired temperature required for washing, whether this be for personal hygiene, food preparation or utensil cleaning.

\subsection{Water wastage by hot water outlet type and for single use}

It was initially decided to investigate the extent to which householders allowed cold water to drain away while waiting for warm water from hot water taps or showers. Out of the 108 respondents, $66 \%$ acknowledged leaving the kitchen hot water tap running to drain cold water before using the water at the preferred temperature. A similar figure was reported for the main hand wash basin $(63 \%)$, while the figure for the main shower was the highest (77\%). A summary of the results is presented in Figure 2, along with the responses concerning hand wash basin 2 and shower 2 . Results for the second showers and hand wash basins need to be treated with caution as they were based on a small sample size ( $n=15$ and $n=33$ respectively).

In order to determine whether the amount of cold water not used before being drained was dependent on outside temperature, a follow up question was given to find out the season(s) when this occurred. It may be the case, for example, that immediately using water upon turning on the hot water tap is more common in summer months than in winter. The results are presented in

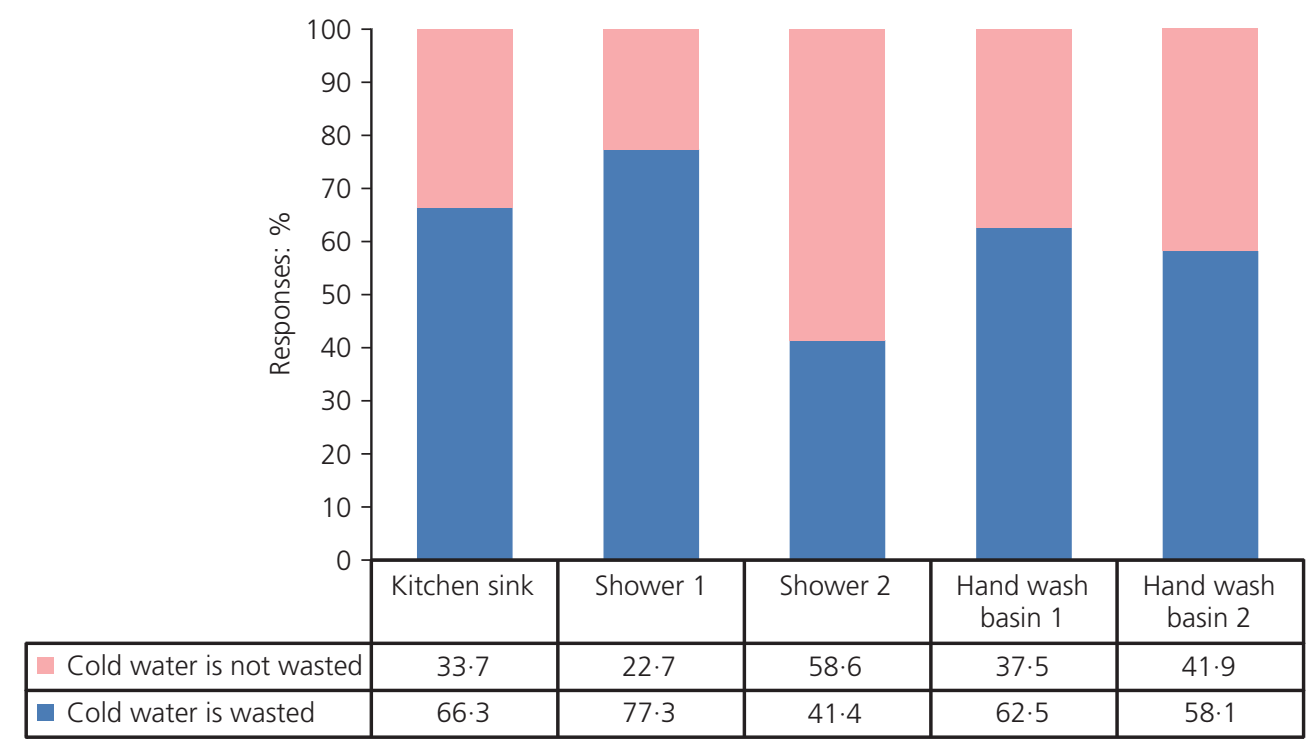

Figure 2. Percentage of responses on whether cold water from domestic hot water outlets is left to drain while waiting for warm water at a temperature preferable for use 
Estimating the amount of cold water

wastage in UK households

Nawaz and Waya
Figure 3 and, as expected, more water is left to drain without first being used in the cooler seasons.

Figure 4 shows the distribution of water being drained without first being used (as ranges) from the five domestic hot water outlets considered in the study. In terms of volumes of water unused before draining, about $48 \%$ of respondents reported volumes of between just over 0 and 11 , and $32 \%$ between just

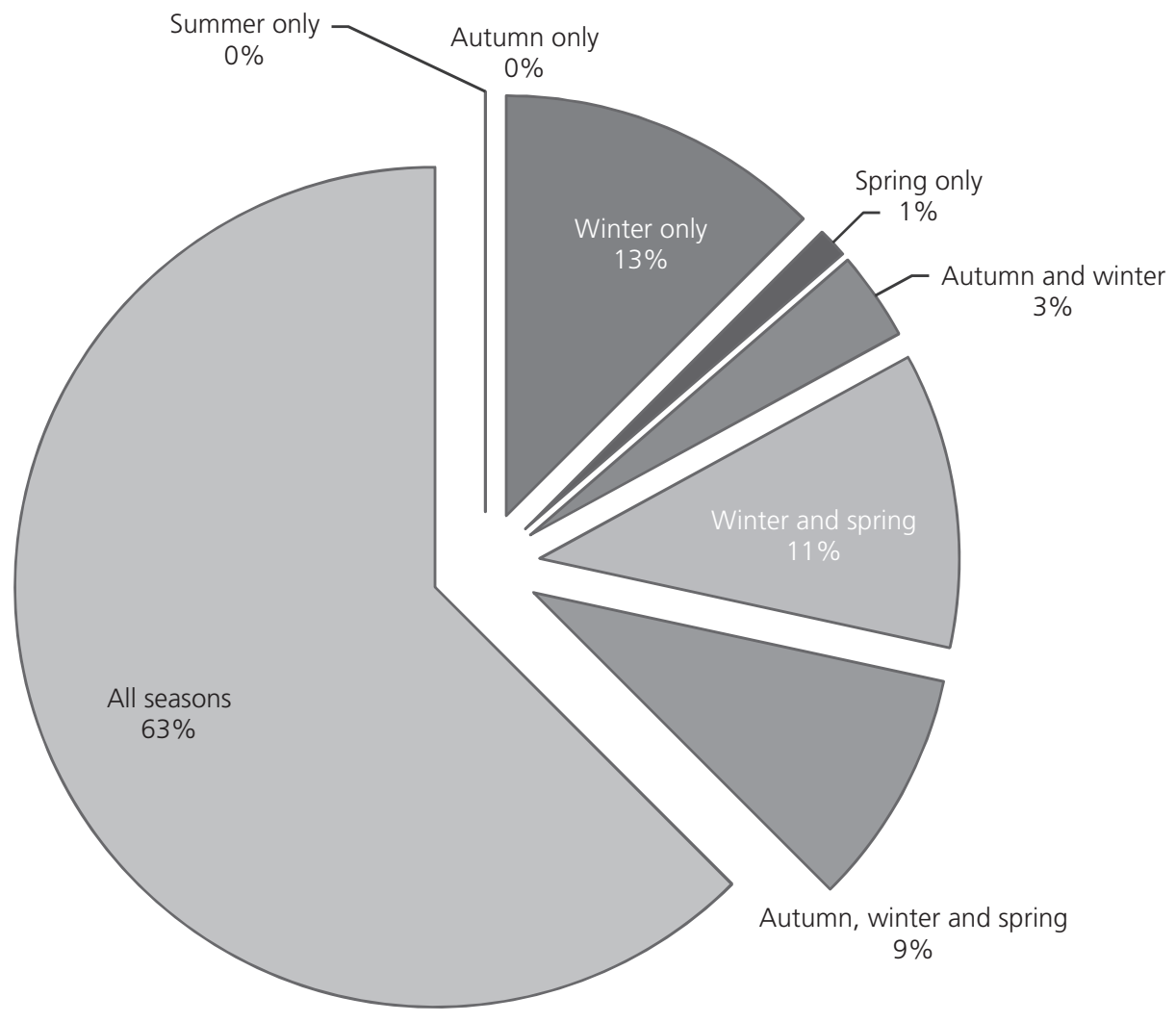

Figure 3. Extent to which the practice of draining unused volumes of water takes place over different seasons

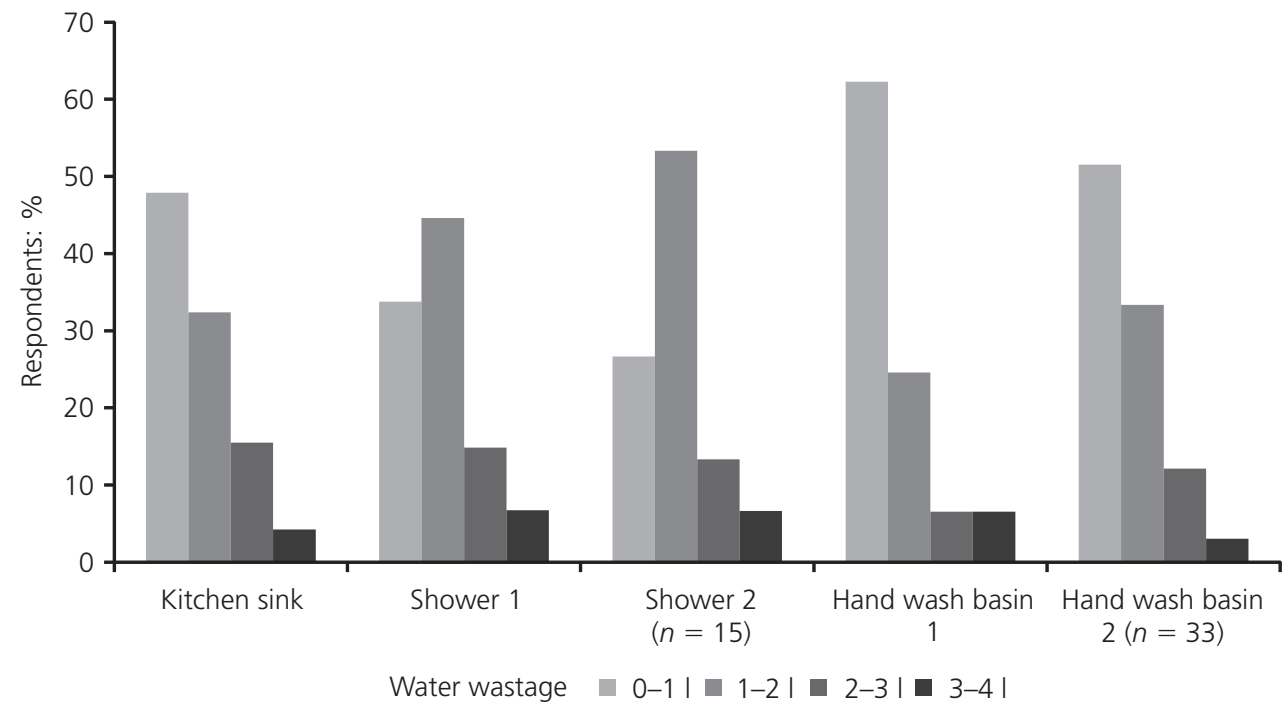

Figure 4. Distribution of unused volume of water drained (indicated as percentage) by domestic hot water outlet type 
over 1 and 21 at the kitchen sink on a single use. For shower 1, $45 \%$ of water drained was within the range of $1-21$ on a single use. It was also found that many householders did not drain a significant volume of water using hand wash basin 1 on a single use $-52 \%$ of respondents indicated draining $0-11$ of water.

Unused water volumes drained are shown for the kitchen sink, shower 1 and hand wash basin 1 in Figure 5. The results for shower 2 and hand wash basin 2 are not included owing to the relatively small sample sizes. The results show that about the same amount of water per single use is being allowed to drain for all three outlets.

\subsection{Per capita unused water drained by hot water outlet type}

Average water volumes drained based on the survey responses were multiplied with average water use frequencies (see Table 1) to determine the total amount of cold water that would potentially be draining from the hot water outlets per person per day. A key assumption was that every time each hot water outlet was used, an equal amount of cold water was drained. In reality, less unused

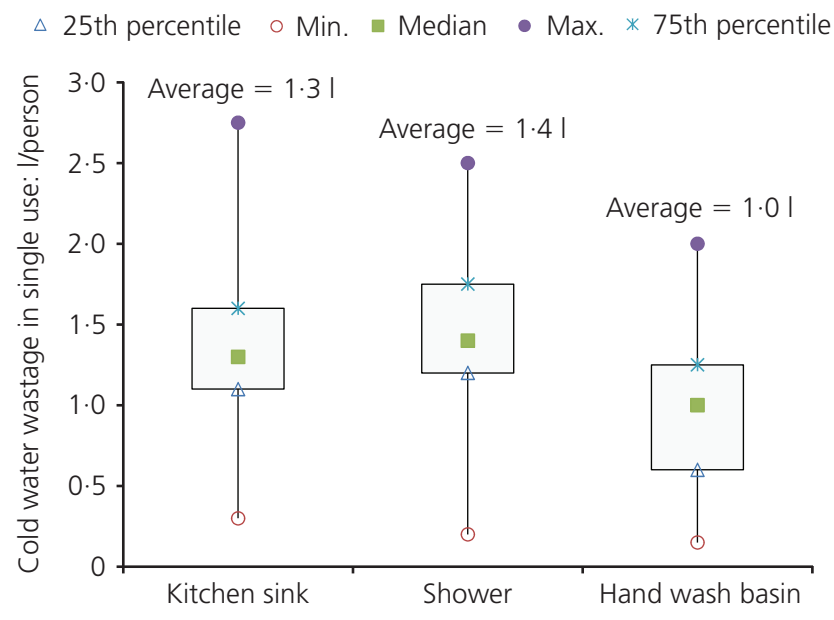

Figure 5. Unused water volume drained from three hot water outlets

\begin{tabular}{|c|c|c|c|c|}
\hline Hot water outlet & $\begin{array}{l}\text { Average use frequency } \\
\text { per person per day }\end{array}$ & $\begin{array}{l}\text { Average unused water } \\
\text { drained per person per day: I }\end{array}$ & $\begin{array}{l}\text { Standard } \\
\text { deviation: I }\end{array}$ & $\begin{array}{c}\text { Average unused water drained as } \\
\text { percentage of average PCC of }\end{array}$ \\
\hline
\end{tabular}

water was likely to be drained during more frequent water use. As shown in Table 1, the kitchen sink had the highest wastage (i.e. an average of 7.51 per person per day).

The combined average unused water drained from the kitchen sink, shower 1 and wash hand basin 1 was 151 per person per day, which translates to $10 \%$ of the average per capita water consumption in UK households (Table 2). Standard deviation values are also presented in the table, given the subjective nature of data collection. These tend to be relatively high in some cases (e.g. hand wash basin 1), suggesting lower confidence in the gathered data.

\subsection{Factors affecting unused water volumes drained from hot water outlets}

Several factors were examined to identify whether they affected or contributed to unused water being drained - distance from boiler to hot water outlets, and type, efficiency rating and age of boiler. Each is now discussed in turn.

\subsubsection{Distance from boiler}

As shown in Table 2, the average distance from the boiler to the kitchen sink was found to be $4.6 \mathrm{~m}$. This was shorter than the distances to all the other hot water outlets, with wash hand basin 2 having the farthest distance of nearly $7 \mathrm{~m}$.

Only a limited number of responses were available for this part of the analysis as many householders had not provided information on the distance of the boiler from the hot water outlets. From the limited data $(n=16)$, no significant direct relationship was found
Hot water outlet

Kitchen sink 4.6

Shower 1

Shower 2

Wash hand basin 1

Wash hand basin 2

Table 2. Average distances of hot water outlets from boiler 150 l: \%

\begin{tabular}{lllll}
\hline Kitchen sink & 5.8 & 7.5 & 5.0 & 5.0 \\
Shower 1 & 1.4 & $2 \cdot 0$ & 1.2 & 1.2 \\
Shower 2 & 1.0 & 1.3 & 0.7 & 0.9 \\
Hand wash basin 1 & 5.2 & 5.5 & 4.3 & 4.5 \\
Hand wash basin 2 & 3.2 & 4.2 & 2.6 & 2.8
\end{tabular}

Table 1. A summary of per capita water wastage from hot water outlets 
between unused water volume drained from the kitchen sink and distance to the boiler. The coefficient of determination $\left(R^{2}\right)$ indicated that only $3.6 \%$ of the total variation in unused water volume drained could be explained by the linear relationship between drained volume and distance of boiler (see Figure 6). Similar results were found when distances from the boiler to shower 1 and hand wash basin 1 were plotted against drained volume. The $R^{2}$ values were $5 \%$ and $2.6 \%$ for shower 1 and wash hand basin 1, respectively, which were still very low to explain the relationship between the two variables.

\subsubsection{Type of boiler}

To determine if there was any difference between type of boiler and the amount of water wasted, a Mann-Whitney test was carried out on samples for the kitchen sink, shower 1 and wash hand basin 1 . This non-parametric test was selected because the samples were not normal when tested using an Anderson-Darling test. Kitchen sink samples with a combi boiler had a mean water wastage of 1.261 , while those with a conventional boiler had a mean water waste of 1.201 ; this test was significant and had a $P$-value of 0.68 . A limitation here was that there were twice as many samples for combi boilers than conventional boilers. The samples for shower 1 under combi and conventional boilers had mean water wastages of 1.61 and 1.31 , respectively, and the test was significant, having a $P$-value of $0 \cdot 26$. Lastly, mean water wastages of 1.01 and 1.11 were found for combi and conventional boilers, respectively, on wash hand basin 1 samples $(P=0.57)$. Figure 7 shows the average water wastage from the three hot water outlets using combi and conventional boiler systems. In all three cases, there was no significant difference between wastage for systems with combi and conventional boilers as all $P$-values were above the $5 \%$ significance level.

\subsubsection{Boiler energy efficiency}

An investigation was carried out into the effect of boiler energy efficiency on water wastage to determine whether more energyefficient boilers resulted in greater water savings. In the survey,

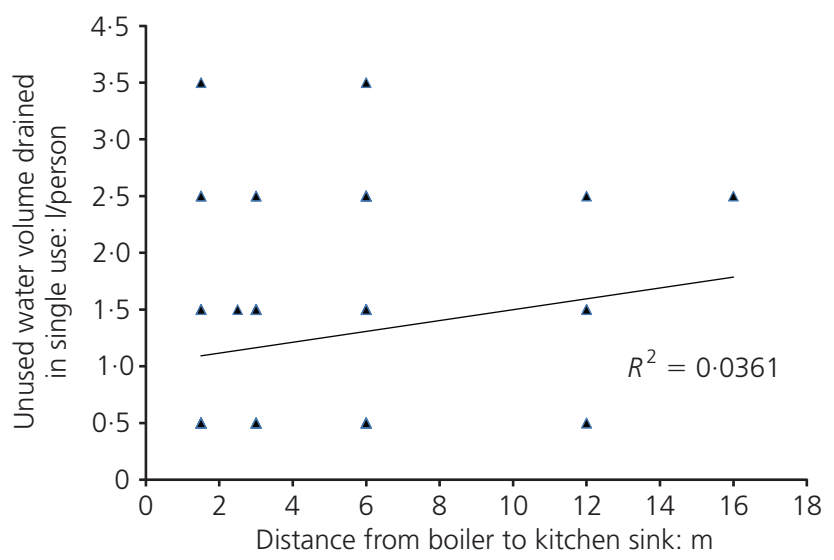

Figure 6. Linear plot of unused water volume drained against distance from boiler to kitchen sink

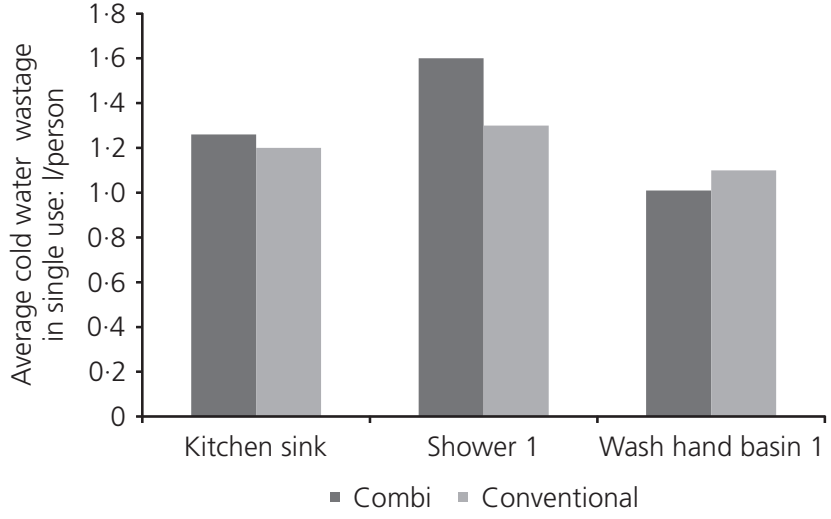

Figure 7. Graphical comparison of means of water wastage from hot water outlets based on boiler type

householders were asked whether their boiler was classified as energy efficient (e.g. condensing boilers are classed as energy efficient). Efficient and inefficient boilers resulted in average water wastages of 0.9 and 1.31 , respectively, at the kitchen sink, with a $P$-value of $0 \cdot 14$. For shower 1 , mean water wastages of 1.41 and 1.61 were obtained for systems with efficient and inefficient boilers, respectively $(P=0.23)$; for hand wash basin 1 , average water wastage figures of 0.711 and 1.041 , respectively, were obtained $(P=0 \cdot 09)$. Although the mean water wastages for systems with inefficient boilers were higher than those with efficient boilers, the $P$-values show that they were not significantly different at the $5 \%$ significance level.

\subsubsection{Age of boiler}

To supplement the energy efficiency findings, it was decided to include boiler age in the analysis to determine whether this had an effect on the amount of water being wasted. Two sets of analyses were undertaken; the first involved 'old and 'new' combi boilers and the second 'old' and 'new' conventional boilers. Boilers of age between 0 and 5 years were classified as 'new', while those of age 6 years and over were classified as 'old'.

For combi boilers, average water wastages of 0.81 and 1.71 were obtained for new combi and old combi boilers, respectively, at the kitchen sink $(P=0 \cdot 001)$. Shower 1 had average water wastage figures of 1.51 and 1.71 for new combi and old combi boilers, respectively, $(P=0 \cdot 20)$. The same test produced mean water wastage figures of 0.81 and 1.31 for new combi and old combi boilers, respectively, for hand wash basin $1(P=0.03)$. These results indicate that mean water wastage was higher for systems with old combi boilers (Figure 8). These differences were found to be generally statistically significant at the $5 \%$ level.

For conventional boilers, Mann-Whitney tests for the kitchen sink with new and old conventional boilers produced mean water wastages of 1.01 and 1.41 , respectively, $(P=0 \cdot 12)$. The corresponding values were 1.11 and 1.51 for shower $1(P=0 \cdot 17)$ and 1.01 and 1.21 for hand wash basin $1(P=0.43)$. While the results 


\section{Offprint provided courtesy of www.icevirtuallibrary.com Author copy for personal use, not for distribution}

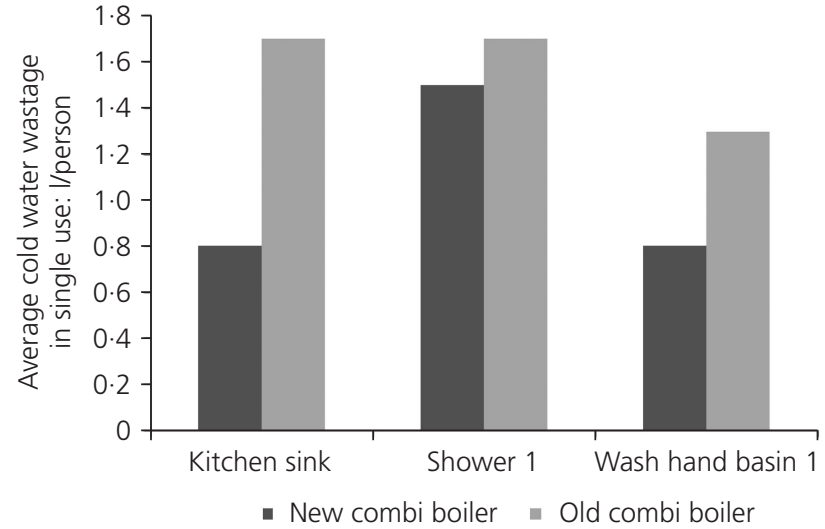

Figure 8. Graphical comparison of means of water wastage from hot water outlets based on age of combi boiler

indicated that wastage was higher for the older boilers, the differences were not statistically significant at the $5 \%$ level.

\subsubsection{Water wastage and frequency of use}

As shown in Table 3, water wastage was significantly reduced as a result of more frequent use of the kitchen sink.

\section{Discussion}

\subsection{Water wastage by type of hot water outlet}

Householders acknowledged wasting cold water in all seasons except the summer. This is expected given that lower air temperatures lead to lower temperatures for inlet water in boilers, meaning that a longer time is needed for boilers to raise the water temperature to preferable levels for use. The results also showed that $63 \%$ of respondents wasted cold water at the kitchen sink, shower 1 and hand wash basin 1 . The highest percentage of responses was for the shower, given the disinclination for many householders to take a cold shower given the cool temperatures in the UK for about 9 months of the year. Nonetheless, the amount of waste being reported is likely to be an underestimate owing to SDR bias. The figure reported for showering, for instance, would suggest that nearly one in four respondents was happy to take a cold shower, which is thought unlikely to be the case.

In terms of volumes of unused water allowed to drain, the average amount for the three hot water outlets (kitchen sink, main shower and main hand wash basin) fell within the range of 1-2 1 . When transforming unused volume drained to daily per capita values, the highest unused volume occurs at the kitchen sink. This is simply

\begin{tabular}{lccccc} 
Time (a.m.) & 8.00 (first use) & 8.05 & 8.15 & 8.30 & 9.00 \\
\hline Wastage: I & 3.6 & 0 & 0 & 0.5 & 0.8
\end{tabular}

Table 3. Water wastage at kitchen sink at various times following first use owing to more frequent use of the kitchen hot water tap. In contrast, the lowest unused volume drained was due to showering, owing to lower use frequency. Despite this, the effects of SDR bias cannot be discounted as higher figures have been reported elsewhere. For example, recent research from the bathroom manufacturer Ideal Standard (Rheinberg, 2012) indicates that, before showering, UK householders let the water run for an average of $78 \mathrm{~s}$ before getting in. Based on assumptions used in this research, this would equate to 6-71 average daily volume of unused water draining away prior to showering. Clearly, the figures presented here are subject to a range of uncertainties, and further investigation is warranted before arriving at firm conclusions.

Total daily per capita wastage was estimated to be 151 from use of the kitchen sink, main hand wash basin and shower. Shower 2 and hand wash basin 2 were not considered here on the assumption that they were either redundant or not used often (as indicated by householder responses). This potential wastage, which is $10 \%$ of the UK average daily PCC is significant, and reducing this could be one way for water companies to help meet the Ofwat target of 20-301 PCC reduction by 2030. It should be noted that a key assumption made at arriving at the above findings was that householders waste the same amount of water every time they use a hot water outlet. However, as shown by results from the preliminary investigation (Table 3), this is unlikely to be true for the kitchen sink owing to higher frequency of use.

\subsection{Factors governing water wastage}

Several factors were examined to identify whether they affected or contributed to water wastage. It was found that the distance of the boiler from the hot water outlet played a minor role in water wastage. However, given the small number of responses $(n=16)$ to the survey question on pipe lengths, this result is not comprehensive, and findings from other studies do not support this. For example, in a study by EST (2008c), the length of piping from the boiler to hot water outlets was found to have an effect on the amount of cold water wasted. Reducing the length of these pipes would lower the amount of cold water stored in the pipe run from the boiler. Alternatively, better insulation would also reduce waste. If pipes entering the boiler are not insulated, the inlet water temperature might be low, especially in the winter. As stated by Grubb (2006), boilers may not heat more water when its temperature is very low. In addition, non-insulated pipes after the boiler allow more heat energy to be lost faster, thereby making the water cool faster as well.

Insulating pipes alone without insulating the house is a nonstarter. It was reported that, by 2008 , about two thirds of the British housing stock did not have sufficient insulation according to modern standards (Palmer and Cooper, 2011). This means that many houses in the UK currently lose more energy faster than they acquire it. Although the insulation of old houses is not straightforward, it is important that minimum standards are set and enforced for every household if both energy and water are to be saved in the future. 


\section{Offprint provided courtesy of www.icevirtuallibrary.com Author copy for personal use, not for distribution}

The amount of water wasted at all three hot water outlets was dependent on boiler type (combi or conventional), with combi boilers leading to more waste from both the kitchen sink and the shower. Although not statistically significant at the 5\% significance level, the largest absolute difference was noted for shower use, perhaps because a higher temperature is required for showering and combi boilers take longer to achieve this. In the case of conventional boilers, the desired temperature is reached simply after expelling the cold water volume within the pipe run.

Energy-efficient boilers tended to generally result in lower water wastage, although the relationships were not significant at the 5\% level. It should be stressed that a limitation here was that the boilers were either categorised as 'efficient' or 'not efficient', and this lack of detailed efficiency categories requires the results to be treated with caution. In contrast, stronger relationships were obtained between combi boiler age and water wastage. It was generally found that newer combi boilers (and hence more efficient boilers) led to lower wastage. This also provides some evidence to suggest that more energy-efficient combi boilers result in less wastage.

The age of conventional boilers did not have any significant effect on water wastage for all the hot water outlets studied. This is to be expected as the primary mechanism for water loss in conventional boiler systems is the discharge of stored cold water within the pipe run.

\subsection{Study limitations}

Having identified potential wastage volumes and possible reasons for this, it is useful to propose recommendations for reducing this wastage. However, such an exercise needs to be approached with caution given the numerous limitations of the study. It should first be noted that the overall aim of the study was to provide a first estimate of the likely volumes of unused water drained and to put this into perspective. It is felt that this has largely been achieved.

What turned out to be more challenging was the identification of reasons for the waste. Issues such as sample size and accuracy of responses to some of the more subjective survey questions meant that there was less clarity on what precisely is leading to the waste. The SDR bias was noted as potentially a key factor in leading to underestimates of the volumes of water being wasted. Lack of metering was a significant limitation, as householders were requested to estimate the timings/volumes of unused water being drained. There is obvious scope for guess work and consequent errors. It is unclear to what extent pipe lengths contribute to the waste, given that accurate relationships between pipe run lengths and water drained could not be established. Children were not included in the study and their possible different water use habits (less frequent showering and hand washing) could have resulted in lower wastage volumes.

\section{Conclusions and recommendations}

Despite the limitations of this study, the problem of unused water being drained from hot water outlets prior to it reaching a desired temperature has been highlighted. A first estimate has also been provided about the scale of the waste. Specifically, the following conclusions can be drawn from the results.

- Almost all householders acknowledged allowing unused water to drain from at least one of the hot water outlets during all seasons except the summer. Nearly two-thirds acknowledged wasting cold water from at least one of the hot water outlets throughout the year.

- The daily average per capita unused water allowed to drain from hot water outlets was estimated to be 151 , which is equivalent to $10 \%$ of the UK's domestic PCC.

- Reasons for wastage were unclear and mixed results were obtained. Boiler age (hence efficiency) and boiler type (whether conventional or combi) were among some of the reasons for waste.

Given the uncertainties associated with the quantitative data gathered in the study, a clear recommendation is that further research is warranted to accurately quantify the water waste taking place. While this research highlighted the issue of cold water wastage in UK households, the data used in this study may clearly not represent all the variations regarding human behaviour in terms of water use and all water heating systems. It is therefore suggested that more studies be carried out that will seek precise information from water users regarding hot water use in the home. In particular, the effect of the frequency of hot water outlet use on wastage needs to be investigated.

To be sufficiently robust, smart metering and temperature sensors would need to be deployed to accurately quantify unused volumes of water being drained. This could also help identify the extent of another problem, sometimes associated with combi boilers, which is that of the water being too hot. These measurements, perhaps taken in conjunction with boiler manufacturers, of the performance of different water heating systems would help attach water efficiency ratings to boilers. The authors strongly believe that boilers should be given a water efficiency rating in addition to an energy efficiency rating. This would help promote the installation of water-efficient boilers in water stressed areas to reduce consumption.

\section{Acknowledgement}

The second author would like to thank the Commonwealth Scholarship Commission for sponsoring the postgraduate study (under scholarship number MWCS-2011-543).

\section{REFERENCES}

Anglian Water (2012) Water Efficiency Self Assessment Guide from Anglian Water. See http://www.anglianwater.co.uk/ (accessed 15/05/2013).

Beal CD and Stewart RA (2011) South East Queensland Residential End Use Study: Final Report. Urban Water Security Research Alliance, Brisbane, Australia, Technical report no. 47 . 
Beal CD, Bertone E and Stewart RA (2012) Evaluating the energy and carbon reductions resulting from resource-efficient household stock. Energy and Buildings 55: 422-432.

CEBR (Centre for Economics and Business Research) (2011) British Gas Home Energy Report 2011, An Assessment of the Drivers of Domestic Natural Gas Consumption. CEBR, London, UK.

Defra (Department for Environment, Food and Rural Affairs) (2008) Future Water. The Government's Water Strategy for England. HMSO, Norwich, UK.

Defra (Department for Environment, Food and Rural Affairs) (2011) Water for Life. White Paper. HMSO, London, UK.

Environment Agency (2008) Water Resources in England and Wales - Current State and Future Pressures. Environmental Agency, Bristol, UK.

Environment Agency (2009) Water for People and the Environment - Water Resources Strategy for England and Wales. See http://www.environment-agency.gov.uk/research/ library/publications/40731.aspx (accessed 15/05/2013).

EST (Energy Saving Trust) (2008a) Measurement of Domestic Hot Water Consumption in Dwellings. See https://www.gov.uk/ government/uploads/system/uploads/attachment_data/file/ 48188/3147-measure-domestic-hot-water-consump.pdf (accessed 15/05/2013).

EST (Energy Saving Trust) (2008b) Quantifying the Energy and Carbon Effects of Water Saving. See http:// www.energysavingtrust.org.uk/Publications2/Housingprofessionals/Heating-systems/Quantifying-the-energy-andcarbon-effects-of-water-saving-full-technical-report (accessed 15/05/2013).

EST (Energy Saving Trust) (2008c) Domestic Heating by Gas: Boiler Systems - Guidance for Installers and Specifiers. See http://www.energysavingtrust.org.uk/Publications2/Housingprofessionals/Heating-systems/Domestic-heating-by-gasboiler-systems-2008-edition (accessed 15/05/2013).

Fidar A, Memon FA and Butler D (2010) Environmental implications of water efficient microcomponents in residential buildings. Science of the Total Environment 408(23): 5828 5835.

Grubb D (2006) Installing On-demand Water Heaters. See http:// goo.gl/uX0nb (accessed 27/07/2012).

HHWT (Heating and Hot Water Taskforce) (2010) Heating and Hot Water Pathways to 2020. See http://www.idhee.org.uk/HHTF.pdf (accessed 15/05/2013).

Jordan D (2012) Save Water Swindon. Phase 1 Evaluation Report. See http://www.waterwise.org.uk/resources.php/50/ save-water-swindon-phase-1-evaluation-report (accessed 15/ 05/2013).

King $M$ and Bruner G (2000) Social desirability bias: a neglected aspect of validity testing. Psychology and Marketing 17(2): 79-103.

MTP (Market Transformation Programme) (2008) BNWAT28: Water Consumption in New and Existing Homes Version 1.0. WRc, Swindon, UK, WRc CP337.

Nakagawa N, Kawamura A and Amaguchi H (2010) Analysis of decreasing tendency of domestic water use per capita in Tokyo. Proceedings of BALWOIS, Water Observation and Information System for Decision Support, Orid, Republic of Macedonia. See http://www.balwois.com/balwois/info_sys/ publication2010.php (accessed 15/05/2013).

NWC (National Water Commission) (2012) Australian Environmental Water Management: 2012 Review. NWC, Canberra, Australia.

Ofwat (2010) Waste Not, Want Not - Making the Best Use of Our Water. Ofwat, Birmingham, UK.

ONS (Office for National Statistics) (2011) National Population Projections, 2010-based Statistical Bulletin. See http:// www.ons.gov.uk/ons/rel/npp/national-population-projections/ 2010-based-projections/stb-2010-based-npp-principal-andkey-variants.html (accessed 15/05/2013).

Palmer J and Cooper I (2011) Great Britain's Housing Energy Fact File. See http://www.eclipseresearch.co.uk/download/ energy/Housing\%20Fact\%20File\%20270911\%20\%20V19.pdf (accessed on 15/03/2013).

Rheinberg T (2012) Stop and Think - Ideal Standard's Water Saving Research 2012. See http://www.bathroomreview.co.uk/in-depth/Ideal-Standards-Water-SavingResearch-2012.php (accessed 15/05/2013).

UoL (University of Leeds) (2008) Draft Amended Guidance upon Ethical Issues. See http://researchsupport.leeds.ac.uk/images/ uploads/docs/UoL_guidance_on_identify_ing_ethical_issues_ (v2).pdf (accessed 15/05/2013).

van de Mortel TF (2008) Faking It: Social Desirability Response Bias in Self-report Research.ePublications@SCU, Lismore, Australia.

Waterwise (2012) Water - The Facts: Why Do We Need To Think About Water? Waterwise, London, UK. See http://goo.gl/ p6ffn (accessed 29/05/2013).

Wickes (2011) Wickes Electric Shower Range. Issue 06/11. See http://www.wickes.co.uk/content/ebiz/wickes/resources/ images/gil/45.pdf (accessed 15/05/2013).

\section{WHAT DO YOU THINK?}

To discuss this paper, please email up to 500 words to the editor at journals@ice.org.uk. Your contribution will be forwarded to the author(s) for a reply and, if considered appropriate by the editorial panel, will be published as a discussion in a future issue of the journal.

Proceedings journals rely entirely on contributions sent in by civil engineering professionals, academics and students. Papers should be 2000-5000 words long (briefing papers should be 1000-2000 words long), with adequate illustrations and references. You can submit your paper online via www.icevirtuallibrary.com/content/journals, where you will also find detailed author guidelines. 